\title{
Students' Perceptions and Attitudes Towards Statistics
}

\author{
Hendrikus Male ${ }^{1, *}$ Jitu Halomoan Lumbantoruan ${ }^{2}$
}

\author{
${ }^{1}$ Universitas Kristen Indonesia \\ ${ }^{2}$ Universitas Kristen Indonesia \\ *Corresponding author. Email: hendrikus.male@uki.ac.id
}

\begin{abstract}
Studying Statistics to a number of students might be very difficult to understand due the lack of knowledge of the statistics and low interest of the subject. However, to some students majoring in mathematics might be easy to comprehend and operate the statistics. This study aimed to find out the students' perceptions and attitudes towards the statistics. The study employed descriptive statistics. The writers collected the data through questionnaire to get the quantitative data. The result of the study showed that in terms of the students' perception towards statistics most of them have stated that they mostly agreed with all the statements dealing with perceptions. This can be seen from the first three statements that they could identify the distribution, measurement, and procedure of doing the statistics. The only thing they disagreed is on the ability to communicate the result of statistics and their perception regarding the easiness of the statistics. In terms of the students' attitudes towards statistics, it is clear that the majority of the students showed their high feeling concerning the statistics. In terms of attitude on cognitive competence, most of them also agreed with the way of thinking to do statistics, understanding it, and requiring a great deal of discipline.
\end{abstract}

Keywords: Perceptions, Attitudes, Statistics

\section{INTRODUCTION}

In university level, undergraduate students study about Statistics and they may get difficulty in operating the statistics and to read the result. The lecture is also a compulsory subject to be taken by the students. This lecture has become a problem to social science students. Unlike science students, most of the social science undergraduate students see this as a problem in their learning of the subject. Based on the discussion to some students, some of them admitted if they have difficulty to understand the statistics when looking at tables. They said they need more time to concentrate on calculation and how to interpret the numbers into words. This is in line what Ashaari et al, (2010) described that the learners have difficulties in comprehending the statistics because of two factors that is the cognitive and noncognitive factors. They further stated that the cognitive factor dealt with intellectuality and the non-cognitive factor had to do with the attitude, perception, interest, expectation and motivation. Hilton, Schau, and Olsen (2004) also said that the attitudes towards statistics might hive impact to the result of academic.

Based on the pre discussion with some of the students in social science class, they mostly stated that statistics is the most challenging subject for them. The subject is important and frightening to some students.
However, they have to learn and study the course because they have to be able to understand the use of statistics in their final writing project. The subject has also become uninteresting because of its challenge therefore, the students become demotivated and showed very less interest to it. Some other may tend to see the subject negatively.

Generally, the most frequently asked question might be why most of undergraduate students still have low proficiency level when dealing with statistics. There can be ample of factors influencing the students' achievements such as attitudes, motivation, anxiety, learning achievements, aptitudes, intelligence, ages, personalities, etc. it is said that students who have positive beliefs may be more excited in doing the statistics. In contrast, those who have negative beliefs would find it very difficult and be ignorant.

The use of statistics in all kinds of discipline of knowledge has now been efficiently implemented. However, to the best of the writers' knowledge, not many studies have been done by the scholars regarding the statistics. In Indonesian context, a very little papers reported about the students' perception about statistics. Afifah and Wicaksana (2014) in their study, they found out that in general the students' perception about the statistics is categorized as good. The writers are therefore interested to conduct a similar study dealing 
with the students' perception and attitudes towards the statistics and this study would be published in international indexed journal. Another study conducted by Cahyawati, Wahyudin, and Prabawanto (2018) pointed out that the result did not show differences in attitudes both the beginning and at the end of learning in each dimension. It neither showed significant relationship between student attitudes to statistics and the result of learning statistics.

\section{LITERATURE REVIEW}

\subsection{Nature of Statistics}

It is believed that statistics essential subject to learn in the field of education. It is studied in not only in level of high schools but also in university level. Statistics is one of the lectures taught in undergraduate level. It helps the students to understand and implement quantitative methods. The statistics itself is a branch of Mathematics. Chattopadhyay and Chattopadhyay (2014) said that there are two main branches of statistics: descriptive and inferential. Descriptive statistics is used to say something about a set of information that has been collected only. Inferential statistics is used to make predictions or comparisons about a larger group (a population) using information gathered about a small part of that population. The study on the perception and attitudes towards the statistics has to do with the cognitive and non- cognitive factors. According to Neisser, et al (1996) that cognitive ability has a strong academic performance. Whereas, non-cognitive factors deal with motivation perseverance, and self-control (see Ncube and Moroke, 2015). In this study the statistics was limited to whether or not the students understand on how to operate the statistics. This study will also be analysed using descriptive statistics.

\subsection{Perceptions}

Perception is another terminology for view or opinion one may perceive on something. It is believed that when the students have positive perception on their learning it may result in a successfulness. This is line with study conducted by Gunawan, Murniarti, and Male (2019). It is found out that the result of the study belongs to good category of perception. However, when they have bad perceptions, it leads to a failure. The term perception in this study refer to the respondents' prior knowledge on how the see the real situation and condition. Gregory (1970) states that perception as a constructive process. He further mentioned that it deals with prior knowledge, experience. Altman, Valenzi and
Hodgets (1985) defined perception as the way people perceive stimulations in such a way as to be interpreted meaningfully. Bond et al (2012 said that perception deals with interaction between cognitive and noncognitive factors. Mandap (2016) conducted a study dealing with gender differences in statistics anxiety, this study showed that mathematics and perception belong to statistics anxiety components. Therefore, perception is essential because it can affect the students' success of learning any subject.

\subsection{Attitudes}

Attitude deals with the way people perceive or react to its environment and is considered important in learning situation and condition. Liau, Kiat, and Nie (2014 said that the class will be much disturbed when it is negative attitude. Zhang and Campbell (2010) said that attitude is a very complex and unique concept, which integrates multiple properties and has different domains. AlMamun, Rahman, and Hossaim (2012) define attitude as a psychological construct which construct and defines a particular behaviour. Similarly, Mensah et al, (2013) said that attitude as a concept focuses on how an individual thinks, acts, and behaves.

A number of researchers have paid their attention on such area of study. (e.g. Zeidner, 1991; Gal, Ginsburg, and Schau, 1997; Schau and Emmioglu, 2012; Montano and Kapsprzyk, 2008; Male, et al., 2020). Another study about student attitudes and conceptions in statistics conducted by Evans (2007) showed a significant correlation. However, the study conducted by Ghulami, Hamid, and Zakaria (2015) showed that the students have to work hard and there was a lot of effort to learn the statistics.

\section{METHODS}

This study is a quantitative research aiming at describe the students' perception and attitudes towards the statistics course in Faculty of Education and Teacher Training. Descriptive statistics was employed for the study and it was collected through questionnaire. The specific purpose of the research is to find out the students' perception and attitudes towards the statistics. In addition, this study will also be helpful for the teachers' candidate who will write their undergraduate thesis later on. The respondents of this study is the students of English education department and Mathematics education department of Faculty of Teacher Training and Education Universitas Kristen Indonesia in 2019/2020 academic year who have already taken the subject of Statistics or introduction to statistics. The sample was taken random clustery technique. The questionnaire that the writers are going 
to use is adapted and modified from Ncube and Moroke (2015). Since it has been tested for its reliability and validity, the writers consider them as already valid and reliable

\section{RESULT AND DISCUSSION}

As the research questions were to find out the students' perceptions and attitudes towards statistics, the following discussion deals with the findings found in this study. The first finding has to do with students' perception Perception towards Statistics $\mathrm{s}$ towards statistics as

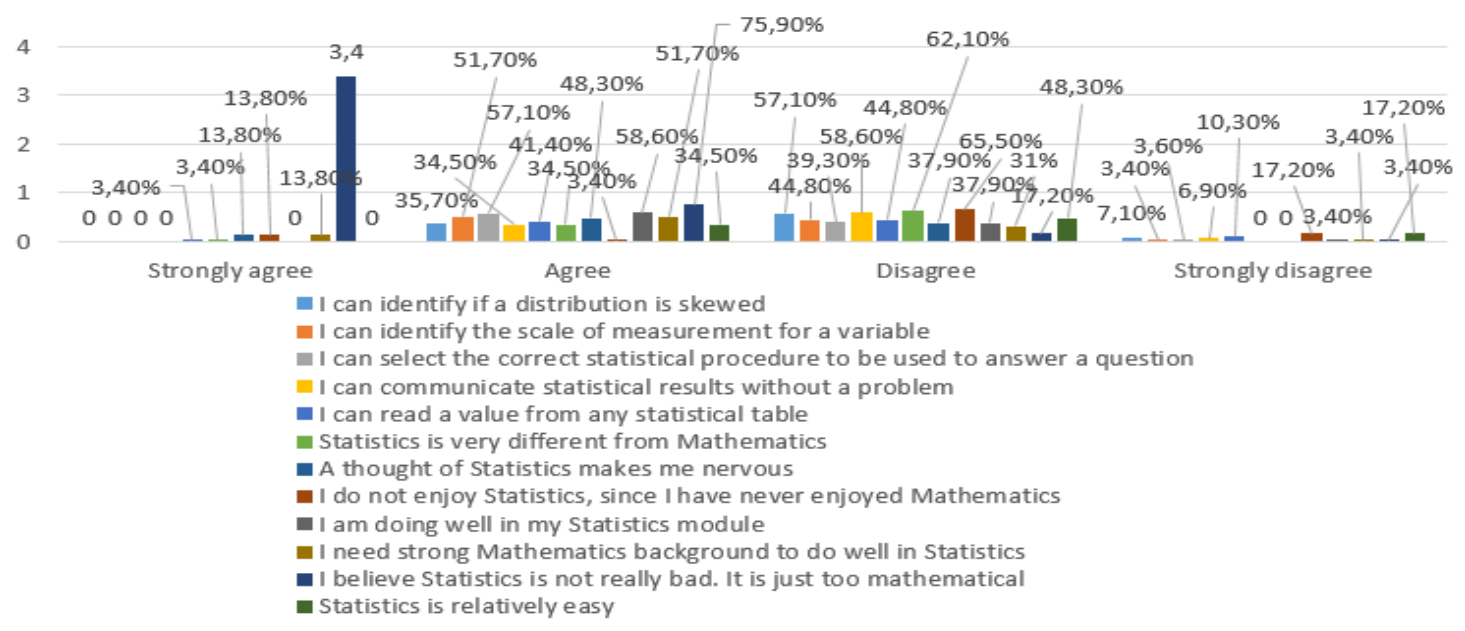
can be seen in Figure 4.1.

Figure 1. Students' Perceptions towards Statistics

Figure 1 indicates that the majority of the students disagreed if they can identify a skewed distribution. This can be seen by the occurrences of disagreement about $(64,2 \%)$. However, most of them $(51,7 \%)$ stated that they agree if they can identify the scale of measurement for a variable. Next, a number of students stated their agreement on selecting the correct statistical procedure to be used to answer a question around $(57,1 \%)$. They then stated that they have difficulty in communicating the statistical results. This can be seen from the disagreement occurrences around (65.5\%). They also stated they can read a value from any statistical table. It can be seen from the occurrence $(55.1 \%)$. Most of them $(62,1 \%)$ also see that statistics is not very different from mathematics. It is also similar with a statement of whether or not statistics makes them nervous and $(62.1 \%)$ of them stated that they disagreed with that. However, a number of the students $(82.4 \%)$ also disagreed if they do not enjoy Statistics, since they have never enjoyed Mathematics. They (58.6\%) also said they are doing well in their Statistics module. In addition, they $(65.5 \%)$ agreed if they need strong Mathematics background to do well in Statistics. They $(79.3 \%)$ also agreed and believed if Statistics is not really bad. It is just too mathematical. They $(65.5 \%)$ also disagreed if Statistics is relatively easy.
The next findings deal with the students' attitudes towards the statistics. In this section the writers divided into 6 subscales based on the In terms of the students' attitudes towards statistics, the attitudes are divided into six subscales such as (a) affect (six items); feeling concerning statistics, (b) cognitive competence (six items): attitudes about intellectual knowledge and mathematical or statistical ability, (c) difficulty (seven items): attitude about difficulty of statistics, (d) value (nine items): attitudes about relevance on worth of statistics in professional and personal life (e) interest (four items): level of interest in statistics, (f) effort (four items): amount of time put in learning statistics. The first students' attitude towards statistics covers the 
feeling concerning statistics as can be seen in Figure 2.

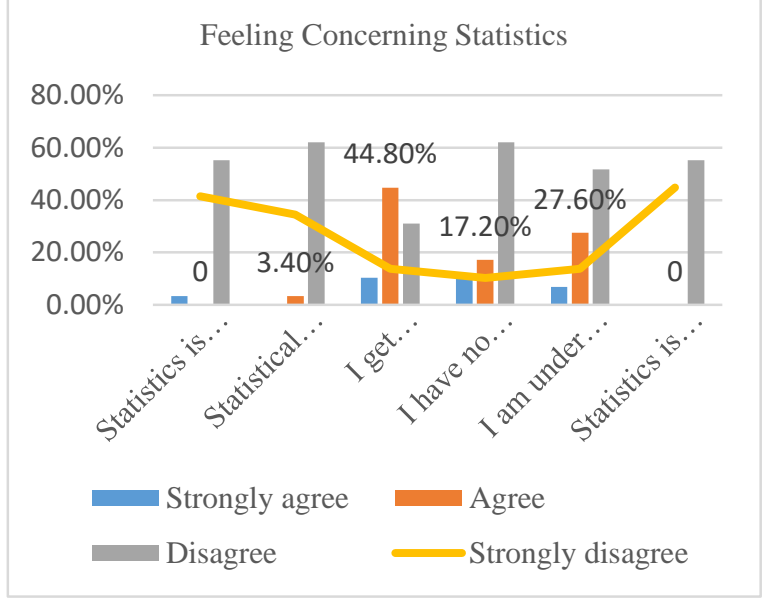

Figure 2. Feeling concerning Statistics

Figure 2 shows that the majority of the students feel concerned regarding the statistics. As the statement stated that the statistics is not useful to their profession, most of them disagreed with the statement. It is around $96.6 \%$ of the students stated that they disagree which means that most of them think that statistics is useful to their profession of their choice. The second statement concerning attitudes of statistical thinking is applicable in their life, outside their job is also similar to the previous statement around $96.6 \%$. However most of them also stated that they get frustrated going over statistics test in class (55.1\%). Next, around $72.4 \%$ of the students stated that they have no idea of what is going on in that statistics course. Next, more than $65.5 \%$ of them stated that they are not under stress during statistics class meaning that they enjoy it. Concerning the statistics whether it is worthless or not, they all disagree. Next, the students' attitudes on cognitive competence. (see Figure 3)

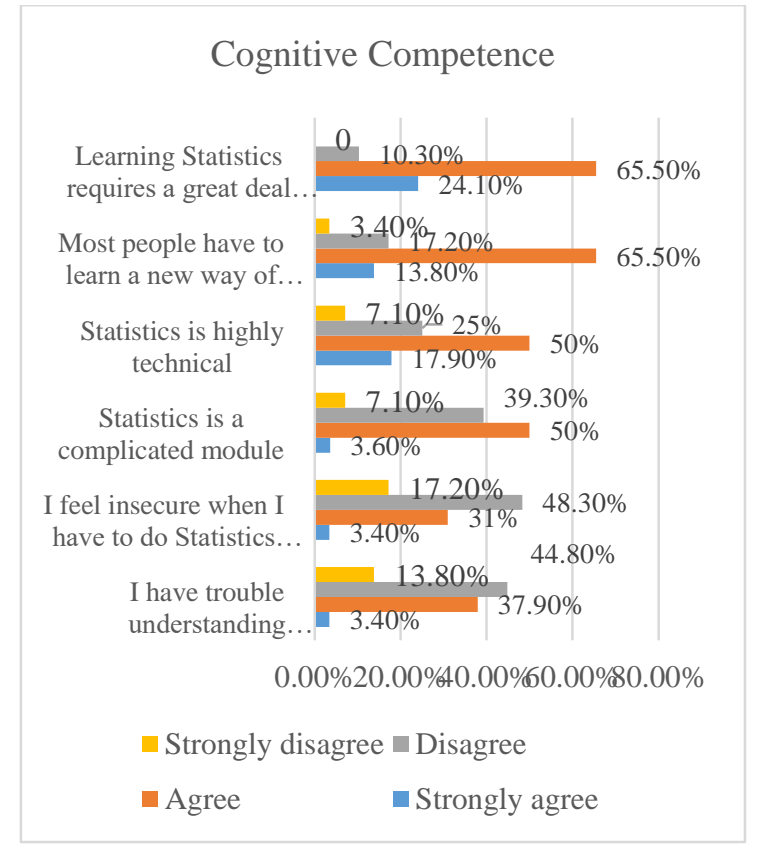

Figure 3. Cognitive Competence

Figure 3 shows that the majority of the students have good understanding regarding their cognitive competence. Most of them (58.6\%) said they disagreed if they have trouble understanding statistics because of how they think. In addition, a number of students $(65.5 \%)$ said that they disagreed if they feel insecure when they have to do statistics problems. Whereas among the students (53.6\%) agreed if statistics is a complicated module. They $(67.9 \%)$ also agreed if statistics is highly technical. A large number of students $(79.3 \%)$ stated that most people have to learn a new way of thinking to do statistics. A large number of students $(89.6 \%)$ also agreed if learning statistics requires a great deal of discipline.

Concerning the difficulty of statistics, it can be seen in Figure

4.

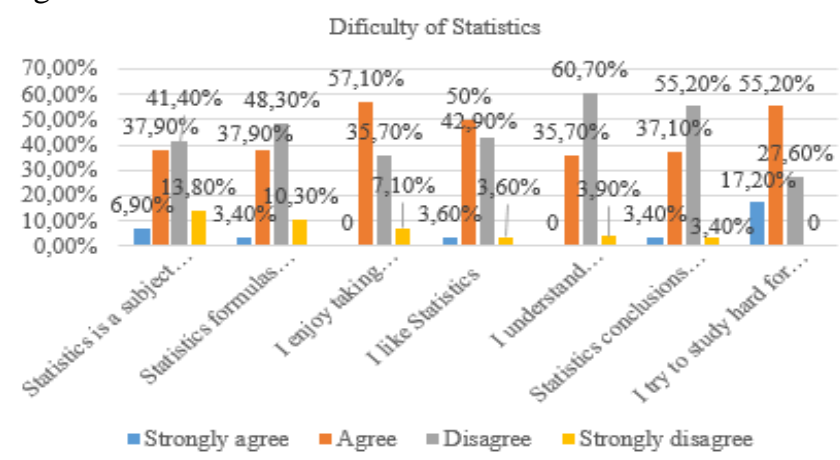

Figure 4. Difficulty of Statistics 
Figure 4 deals with the difficulty on statistics. It shows that the majority of the students $(55.2 \%)$ disagreed if statistics is a subject quickly learned by most people. It is around $58.6 \%$ of the students stated that they also disagreed if statistics formulas are easy to understand. Whereas most of them $57.1 \%$ agreed if they enjoyed taking Statistics modules. This is in line with next statement that $53.6 \%$ of the students also agreed if they liked statistics. However most of them (64.6\%) disagreed if they understand statistics equations. They (58.6\%) also disagreed if statistics conclusions are rarely presented in everyday life. And around (72.4\%) of them agreed if they try to study hard for every statistics test.

Next, the students' attitudes on relevance on worth of statistics in professional and personal life. (see Figure 5)

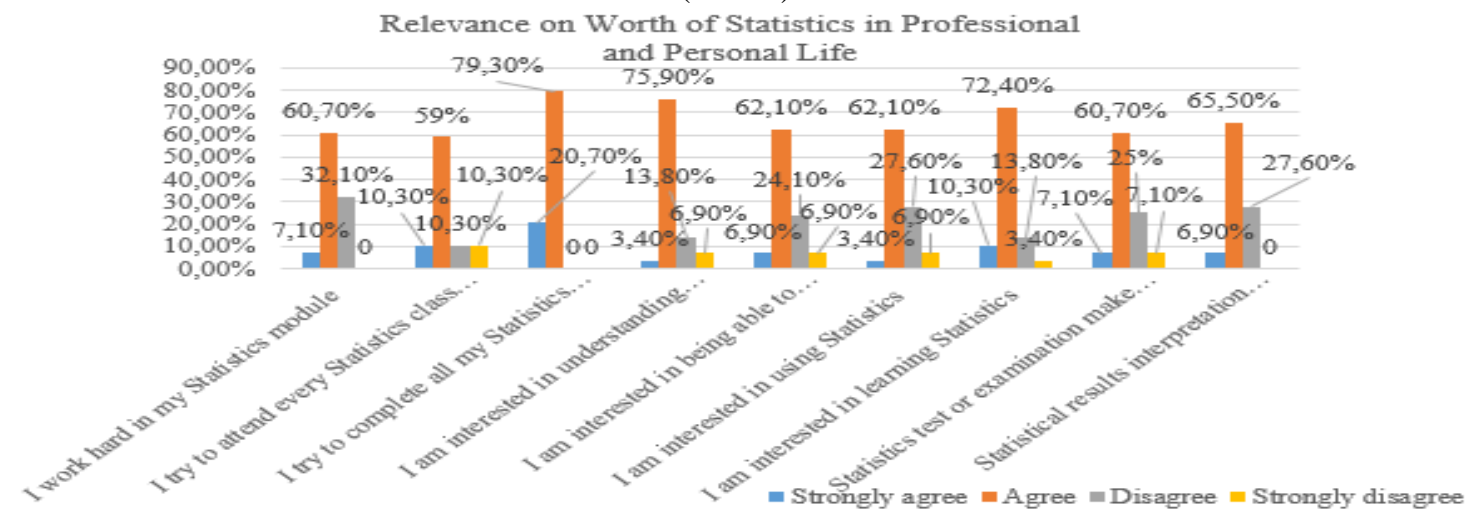

Figure 5. Relevance on Worth of Statistics in Professional and Personal Life

Figure 5 points out attitudes about relevance on worth of statistics in professional and personal life and the majority of the students have good attitude on it. Most of them $(67.8 \%)$ said they agreed if they work hard in their statistics module. They $(69.3 \%)$ also agreed if they try to attend every statistics class session. In addition, all of them $(100 \%)$ agreed if they try to complete their statistics assignments. Next, in terms of their interest, most of them shows agreement on the attitudes. It can be seen in their statements. A number of the students $(79.3 \%)$ agreed if they are interested in understanding statistical concepts. They $(69 \%)$ also stated if they are interested in being able to communicate statistical information to others. Regarding their interest on using the statistics, $65.5 \%$ of the students agreed if they have such interest on statistics. The students $(82.7 \%)$ also agreed if they are interested in learning the statistics. In addition, a number of students $(67.8 \%)$ said that they agreed if statistics test or examination make them anxious. They $(72.4 \%)$ also agreed if Statistical results interpretation make them nervous.

The next discussion deals with the students' attitudes on level of interest of statistics. It can be seen in following Figure 6.

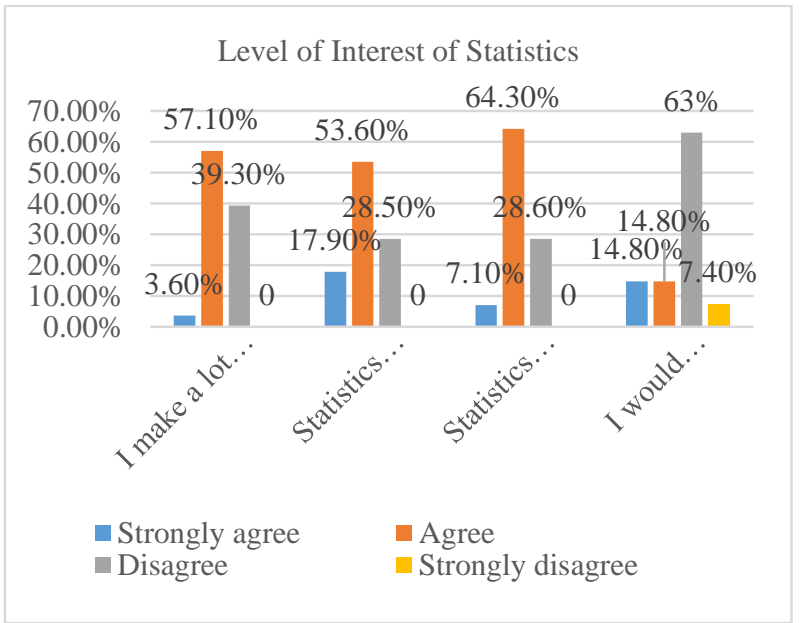

Figure 6 shows that the majority of the students have their level of interest of statistics. Most of them $(60.7 \%)$ said they agreed if they make a lot of mathematical errors in statistics. In addition, a number of students $(71.5 \%)$ said that they agreed if statistics involves massive computations. Next, they $(71.9 \%)$ also agreed if statistics should be a required part of my professional training. Whereas among the students $(70.4 \%)$ disagreed 


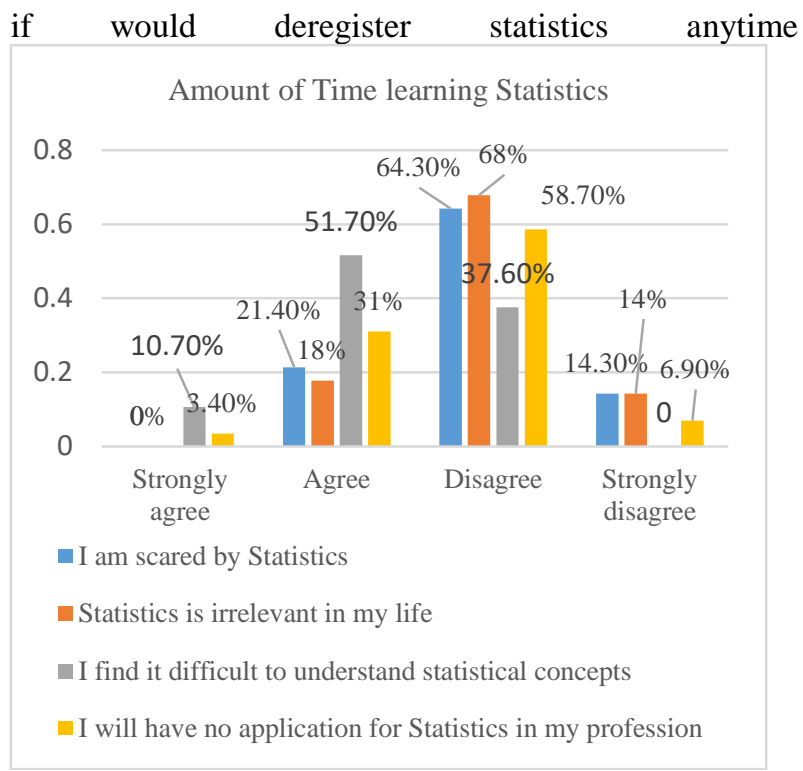

Figure 7. Amount of Time Learning Statistics

Table 7 deals with the amount of time put in learning statistics. It shows that the majority of the students (78.6\%) disagreed if they are scared by statistics. They $(82.2 \%)$ also disagreed if statistics is irrelevant in their life. Whereas most of them $(62.4 \%)$ agreed if they find it difficult to understand statistical concepts. Next, most of them $(65.5 \%)$ disagreed if they will have no application for statistics in their profession.

\section{CONCLUSION AND SUGGESTION}

\subsection{Conclusion}

Based on the findings data analysis and discussion, it is concluded that in terms of the students' perception towards statistics most of them have stated that they mostly agreed with all the statements dealing with perceptions. This can be seen from the first three statements that they could identify the distribution, measurement, and procedure of doing the statistics. The only thing they disagreed is on the ability to communicate the result of statistics and their perception regarding the easiness of the statistics. In terms of the students' attitudes towards statistics, it is clear that the majority of the students showed their high feeling concerning the statistics. In terms of attitude on cognitive competence, most of them also agreed with the way of thinking to do statistics, understanding it, and requiring a great deal of discipline.

Next, concerning the difficulty of statistics even though they enjoy and understand the formula of statistics. In terms of attitudes about relevance on worth of statistics in professional and personal life, most of the students said that they work hard for their statistics module and they would complete all the assignments. Although they stated that they are interested in using statistics, the test and results interpretations would make them anxious.

\subsection{Suggestion}

As the presents study is to find out the students' perceptions and attitudes towards statistics, teachers or lecturers of statistics are hoped to encourage the students as well as varying the way they teach the statistics in simple and fun way so that all the difficulties may be minimized. For future research, it is suggested to conduct similar study in order to enrich the knowledge and to find out what has been left for a betterment.

\section{ACKNOWLEDGMENTS}

The writers would like to thank Universitas Kristen Indonesia who financially supported this study and all the students who have participated.

\section{REFERENCES}

[1] Afifah, S. N., \& Wicaksana, E. J. (2014). Persepsi mahasiswa tentang mata kuliah statistik serta pengaruhnya terhadap prestasi belajar statistik mahasiswa IKIP PGRI Madiun. Jurnal CARE, 1-8

[2] Al-Mamun, A., Rahman, M., Rahman, A. R., \& Hossaim, A. A. (2012). Students' attitudes towards English: The case of life science school of Khulna university. International Review of Social Sciences and Humanities, 3, 200-209.

[3] Altman, S., Valenzi, E., \& Hodgetts, R. M. (1985). Organizational behavior: Theory and practice. Orlando: Academic Press, Inc.

[4] Ashaari, N. S., Judi, H. M., \& Tengku Wook, T. M. (2011). Student's Attitude Towards Statistics Course. Procedia - Social and Behavioral Sciences, $\quad 18, \quad 287-294$. doi:10.1016/j.sbspro.2011.05.041

[5] Chattopadhyay, A. K., \& Chattopadhyay, T. (2014). Introduction to statistics. Springer Series in Astrostatistics, 3, 91-108. doi:10.1007/978-14939-1507-1_2

[7] Evans , B. (2007). Student attitudes, conceptions, and achievement in introductory undergraduate college statistics. The Mathematics Educator, 17(2), 24-30.

[8] Gal, I., Ginsburg, L., \& Schau, C. (1997). Monitoring attitudes and beliefs in statistics education. In I. Gal, \& J. B. Garfield, The 
assessment challenge in statistics education (pp. 37-51). Amsterdam: IOS Press.

[9] Ghulami, H. R., Hamid, M. R., \& Zakaria, R. (2015). Students' Attitudes towards Learning Statistics. AIP Conference Proceeding, 050035. doi:10.1063/1.4915668

[10] Gunawan, R., Murniarti, E., \& Male, H. (2020). Teacher's perception of Physical, verbal, and nonverbal bullying behavior in elementary school. ICCIRS. Manado, Indonesia. doi:http://dx.doi.org/10.4108/eai.11-122019.2302614

[11] Hilton, S. C., Schau, C., \& Olsen, J. A. (2004). Survey of Attitudes Toward Statistics: Factor Structure Invariance by Gender and by Administration Time. Structural Equation Modeling: A Multidisciplinary Journal, 11(1), 92109. doi:10.1207/S15328007SEM1101_7

[12] Humairah, S. (2017). The effect of using Edmodo application to foster students' writing of Narrative text. 1-106. Retrieved from http://repository.uinjkt.ac.id/dspace/handle/123456 $789 / 41910$

[14] Liau, A. K., Kiat, J. E., \& Nie, Y. (2014). Investigating the Pedagogical Approaches Related to Changes in Attitudes Toward Statistics in a Quantitative Methods Course for Psychology Undergraduate Students. Asia-Pacific Education Researcher, 24(2), 319-327. doi:10.1007/s40299014-0182-5

[16] Male, H., Murniarti, E., Simatupang, M. S., Siregar, J., Sihotang, H., \& Gunawan, R. (2020). Attitude of Undergraduate Student's towards Online Learning during Covid-19 Pandemic.
Palarch's Journal of Archaeology of Egypt/Egyptology, 17(4), 1628-1637. Retrieved from

https://www.archives.palarch.nl/index.php/jae/artic le/view/1746

[17] Mandap, C. M. (2016). Examining gender differences in statistics anxiety among college students. International Journal of Education and Research, 4(6), 357-366.

[18] Mensah, J., Okyere, M., \& Kuranchie, A. (2013). Students attitude towards mathematics and performance: Does the teacher attitude matter? Journal of Education and Practice, 3, 132=139.

[19] Ncube, B., \& Moroke, N. D. (2015). Students'perceptions and attitudes towards statistics in south African university: An exploratory factor analysis approach. Journal of Governance and Regulation, 4(3), 231-240.

[20] Neisser, U., Boodoo, G., Bouchard, T. J., Boykin, A. W., Brody, N., Cesi, S. J., \& Urbina, S. (1996). "Intelligence: Knowns and unknowns". American Psychologist, 51(2), 77-101.

[21] Schau, C., \& Emmioglu, E. (2012). Do introductory statistics courses in the United States improve students' statistics? Statistics Education Research Journal, 11(2), 86-94.

[22] Zeidner, M. (1991). Statistics and mathematics anxiety in social science students: Some interesting parallels. British Journal of Educational Psychology, 61, 319-328.

[23] Zhang, D., \& Campbell, T. (2010). The psychometric evaluation of a three-dimension elementary science attitude survey. Journal of Science Teacher Education. 